\title{
Stakeholders' Interest and Attitudes toward Genomic Medicine and Pharmacogenomics Implementation in the United Arab Emirates: A Qualitative Study
}

\author{
Azhar T. Rahma ${ }^{a}$ Iffat Elbarazi ${ }^{a} \quad$ Bassam R. Alib, c George P. Patrinos ${ }^{b, c, d}$ \\ Luai A. Ahmeda, c Fatima Al-Maskaria,c \\ anstitute of Public Health, College of Medicine \& Health Science, UAE University, Al Ain, United Arab Emirates; \\ ${ }^{b}$ Department of Genomics and Genetics, College of Medicine \& Health Science, UAE University, \\ Al Ain, United Arab Emirates; 'Zayed Center for Health Sciences, UAE University, AI Ain, United Arab Emirates; \\ ${ }^{d}$ Department of Pharmacy, School of Health Sciences, University of Patras, Patras, Greece
}

\section{Keywords}

Attitude $\cdot$ Barriers $\cdot$ Mendelow's matrix · Genomic medicine · Pharmacogenomics · Implementation · PESTLE

\begin{abstract}
Background and Aim: Mapping the power, interest, and stance of stakeholders is a cornerstone for genomic medicine implementation. In this study, we aimed at mapping the power/interest of various stakeholders in United Arab Emirates (UAE) and exploring their attitudes toward pressing health genomics aspects. The overarching aim of this study is to facilitate the construction of a road map for the full implementation of genomic medicine and pharmacogenomics in the UAE with potential applicability to many healthcare systems around the world. Methods: A qualitative approach using in-depth interview was employed. Heterogeneous stakeholders were identified by experts in the field. The analysis of the data was a hybrid of deductive and inductive approach using NVivo software for coding and analysis. $R \boldsymbol{e}$ sults: 13 interviews were conducted. Following mapping the Mendelow's matrix, we categorized the stakeholders in UAE to promoter, latent, defender, and apathetic. Most of the in-
\end{abstract}

karger@karger.com www.karger.com/phg

Karger $\frac{1}{6}$

GOPEN ACCESS
(C) 2021 The Author(s)

Published by S. Karger AG, Basel

This is an Open Access article licensed under the Creative Commons Attribution-NonCommercial-4.0 International License (CC BY-NC) (http://www.karger.com/Services/OpenAccessLicense), applicable to the online version of the article only. Usage and distribution for commercial purposes requires written permission. terviewed stakeholders emphasized the clinical demand for genomic medicine in UAE. However, many of them were less inclined to articulate the need for pharmacogenomics at the moment. The majority of stakeholders in UAE were in favor of building infrastructure for better genetic services in the country. Stakeholder from an insurance sector had contradicting stance about the cost-effectiveness of genomic medicine; the majority were concerned with the legal and ethical aspects of genomic medicine and had an opposing stance on direct-to-consumer kits. Conclusions: Implementing the Mendelow's model will allow the systematic strategy for implementing genomic medicine in UAE. This can be achieved by engaging the key players (promoters and defenders) as well as engaging and satisfying the latent stakeholder.

(C) 2021 The Author(s)

Published by S. Karger AG, Basel

\section{Introduction}

It has been 16 years since the first milestone of genomic medicine and pharmacogenomics occurred in 2004, when the FDA approved Gefitinib for the treatment of genetic mutation metastatic non-small cell lung cancer 
[1]. Cornucopia of studies had emphasized the evidencebased value of genomic medicine and pharmacogenomics in breadth of spheres like oncology, neurology, pediatric, and nephrology [2-9]. For example, genomics took center stage recently in the COVID-19 pandemic and proved its value with sequencing the coronavirus genome [9-11]. Despite these leitmotif evidences, still there is a chasm between research and the full implementation of genomic medicine and pharmacogenomics in clinical practice [12-15]. Extensive research efforts have investigated and diagnosed factors associated with the slow-uptake of the full implementation of genomic medicine and pharmacogenomics, and they concluded that gap in knowledge of healthcare providers, current policy challenges, reimbursement of the cost of genetic tests, stance of stakeholders is some of the attributes that hampered the full pragmatic implementation of genomic medicine and pharmacogenomics internationally $[12,13,15-18]$.

Directing the lens to the Middle East and North Africa region, we are introduced to additional and unique challenges. A perspective paper by Zgheib et al. [19] mapped the landscape of precision medicine as well as the gap, challenges, and needs in low- and middle-income countries. The researchers projected the model of "fast-second winner" that recommends pursuing country-specific genome-wide association. This approach claims to create rapport with stakeholders and accelerates the implementation of genomic medicine in the region.

For effective introduction, setting up, and implementation of genomic medicine and pharmacogenomics, we cannot lose sight of the pivotal role of stakeholders [2023]. 14 stakeholders were identified as key players in the micro-, meso-, and macro levels of genomic medicine and pharmacogenomics [21]. Mapping the power, interest, and stance of aforementioned stakeholders is a mainstay in the endeavor of full genomic medicine and pharmacogenomics implementation [20-23].

Different tools, procedures, frameworks, and models are used to map the stakeholders' interest, power, and stance. Mendelow's matrix, policy maker, and PMP stakeholder management are examples of these tools [24-28]. Moreover, some of these tools had been previously employed and validated on the stakeholders of genomic medicine and pharmacogenomics to offer a vantage point for the systematic implementation of genomic medicine and pharmacogenomics [25, 29-31].

There are several studies in United Arab Emirates (UAE) about genomic medicine [32-36]. Nevertheless, no studies about mapping the power, interest, and the attitude of the various stakeholders in the UAE pertaining to the implementation of genomic medicine and pharmacogenomics have been conducted. Therefore, in this study, we aimed at mapping the power/interest of various stakeholders in UAE using the Mendelow's matrix. Additionally, we aimed to explore their attitude and stance toward pressing genomics' aspects. This is to facilitate constructing a roadmap for the full implementation of genomic medicine and pharmacogenomics in the country.

\section{Materials and Methods}

A qualitative approach using in-depth interview had been used to explore the power, interest, and the attitude of the stakeholders in the UAE toward pressing health genomics aspects. Various stakeholders were identified by experts in the field of epidemiology, genomic medicine and pharmacogenomics, and public health. The criteria of selecting the stakeholders are mainly involved in the micro-, meso-, and macro-pillars of the infrastructure of genomic implementation.

The interview guide had been constructed and then revised by experts in the field of genomic medicine, public health, qualitative study, and epidemiology. We employed the inverted pyramid format for the interview guide, and it is composed of blended openended and closed-ended questions and prompts that gauge the attitude, commitment, power, and interest of the stakeholders toward genomic medicine and pharmacogenomics in UAE, as well as their legal and ethical concerns. The following are the focal points of the interview:

- Clinical demand for genomic medicine and pharmacogenomics in UAE.

- Infrastructure preference (in-house or outsource outside the country).

- Opinion whether genomic medicine/pharmacogenomics is cost-effective.

- Implementation approach: preemptive approach or gene-specific approach.

- Attitude about their desire to undertake genetic test.

- Attitude toward online direct-to-consumer kits.

- Concerns about the ethical and legal aspects of genomic medicine in UAE.

Their perceived barriers and challenges for the full implementation of genomic medicine and pharmacogenomics in UAE. The study sampling method was mainly purposive. Snowball technique was used to connect with some stakeholders. 13 in-depth semi-structured interviews were conducted with the identified stakeholders by the first author. All 13 interviews were audio recorded, and field notes were logged during and after the interview. This study had been approved by social science research Ethics Committee of United Arab Emirates University (UAEU) ERS_2017_5671. Participants were asked to read the information sheet of the study as well as to sign the consent form before starting the interview. Each semi-structured interview lasted from 40 to $60 \mathrm{~min}$ and was conducted in a location convenient to the stakeholder.

A verbatim transcription for all interviews was reviewed by 2 researchers and then was returned for random participants for comments and or corrections to ensure credibility and reflexivity. 
Fig. 1. Representation of the interviewed stakeholders.

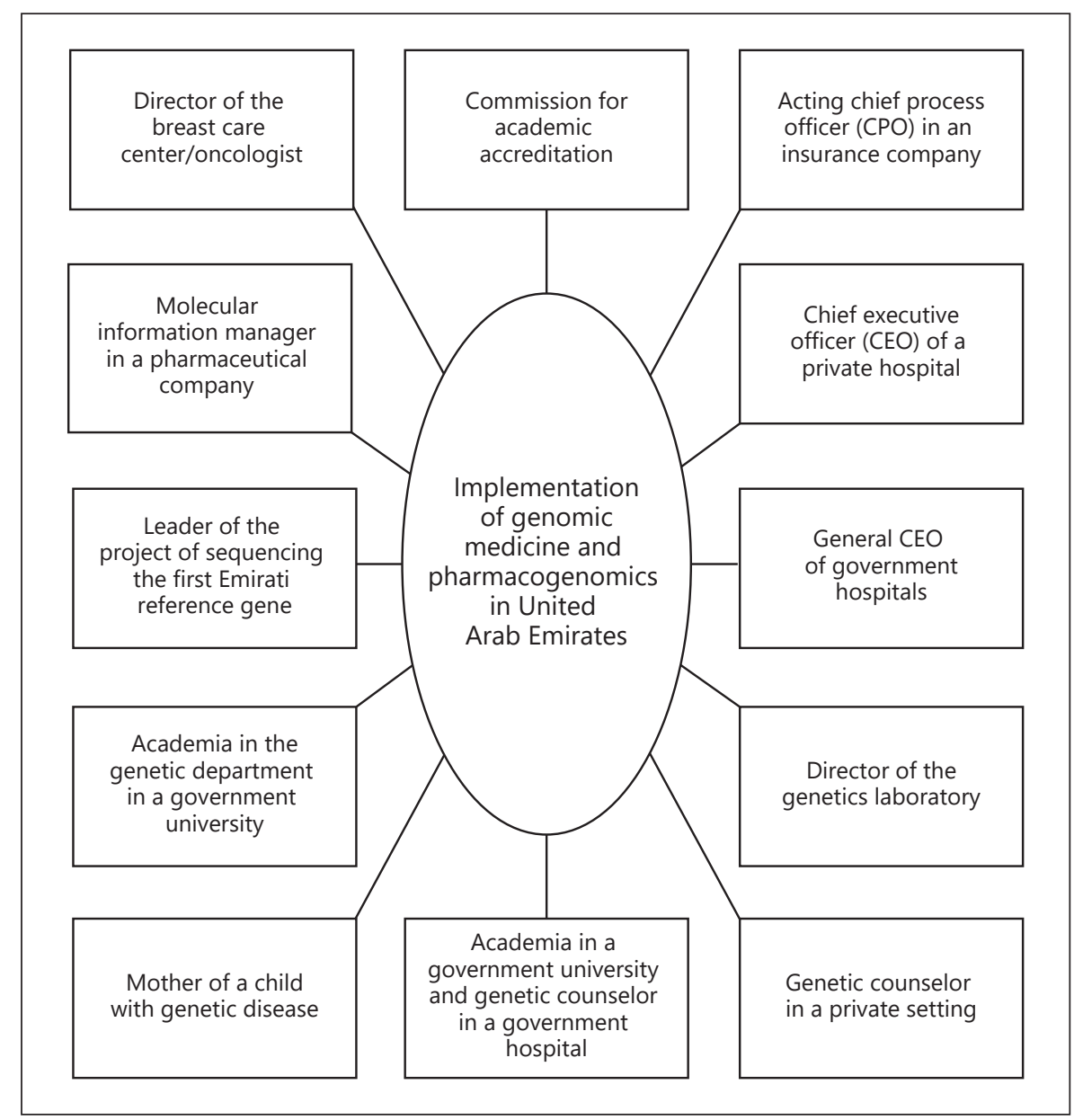

The analysis of the qualitative research data was a hybrid of inductive grounded theory approach informed by Strauss and Corbin [37] to formulate the themes and concepts and deductive using the matrix framework of Mendelow for mapping the interest and power of stakeholders [24].

Inter-coder reliability was ensured. Transcription was uploaded on NVivo 12 software for analysis to extract themes and visualize the findings. A tally matrix was created to signify the preponderance of categories and to isolate outliers and provide decisive confidence [38]. We followed the standards for reporting qualitative research checklist by O'Brien et al. [39] COREQ for presenting our findings.

\section{Results}

Thirteen in-depth semi-structured interviews were conducted. The stakeholders interviewed are presented in Figure 1. The identified main themes extracted inductively from the iterative analysis of the aforementioned stakeholder's interviews are the attitude of the stakeholders toward a variety of facets of genomic medicine and pharmacogenomics. Besides the second main theme which is their perceived barriers and challenges for the full implementation of genomic medicine and pharmacogenomics in UAE. In addition, we underscored an emerging theme of the role of both genetic counselors and the media in the implementation of genomic medicine and pharmacogenomics in UAE which will be annotated under the emerging themes.

\section{Main Themes}

A.1. Attitude of the Stakeholders toward a Variety of Facets of Genomic Medicine and Pharmacogenomics:

\section{Subthemes}

A.1.1. Attitude of Stakeholders about the Clinical Demand for Genomic Medicine and Pharmacogenomics in UAE:

Most of the interviewed stakeholders emphasized the clinical demand for genomic medicine in UAE due to arrays of justifications like the prevalence of consanguinity 
in UAE, the high burden of genetic diseases, the urge to utilize the genomic technology to personalized medications, and the raise in awareness among physicians about the power of genetic services that motivated them to demand genomic medicine.

"Yes, we need genomic medicine in the UAE because we have very young patients with cancer, like from my own practice, the prevalence of breast cancer in very young patients is higher in UAE than western world, I am trained in Germany and I didn't see this much." Stakeholder\#1

"The opportunity here is unique, because once you identify 1 patient you are actually serving a big family as they all share the DNA and that open the door for prevention of the genetic disease." Stakeholder\#5

In terms of the demand to pharmacogenomics, many of the stakeholders were less inclined to articulate the need for pharmacogenomics at the moment; however, they believe that a shift in the demand may occur in the future.

"Pharmacogenomics currently is very limited, you know there are various factors to that, you know it is not widely used but again there will be more demand in the future." Stakeholder\#2

\section{A.1.2. Inclination about the Infrastructure}

to Implement Genomic Medicine and

Pharmacogenomics in UAE:

The majority of stakeholders in UAE favored building the genetic testing??? infrastructure in UAE rather than sending the samples for testing abroad. They vindicated this stance to variable factors of cost, confidentiality, building database, and logistics. Whereas few stakeholders opt to postpone building infrastructure in UAE till the demand increases in order to have return on investment.

"It should be local. I think because one panel at a time will cost. because when you send them outside you usually send them one at a time, so that will cost more and you add more cost to the hospital and the patient, and those people are not geneticist they don't speak the language, so you can't talk directly to the lab, so that result in communication gap and delay communication and hence diagnosis, that in the logistic side.

Another side, is when you have a lab in house you build your own database, currently all testing is done in Portugal, in Germany, so no one knows what is the most common mutation in UAE, having this database will help you plan where to put your resources, treatment." Stakeholder\#5

"I am here to build internal capacity in UAE, internal capacity means: people, infrastructure, science, international recognition and these elements are very important.
So whether we are going to have another genome sequencing center? probably not, but those will have small scale, for example Al-Ain has the ability to have breast cancer diagnostic center, so it would be more like diagnostic of focus areas, but the diagnostic lab that we are building will have broader scale of tests and will cover the population need, so I see it as constant collaboration between all of us, we will not stand alone on high tower, we need to connect to meet the locals need." Stakeholder\#9

"so at the moment as you know, samples are sent-out, when you are doing enough volume it is cheaper to do it in-house, doing few it is easier and cheaper to send it out." Stakeholder\#8

A.1.3. Demeanor of Stakeholders about the Cost-Effectiveness of Genomic Medicine and Pharmacogenomics:

Most of the stakeholders in UAE agreed that genomic medicine and pharmacogenomics are cost-effective, and some were able to bring evidence from their current practice or cited published papers that support that. One of the stakeholders is in the process of studying this in UAE and got the green light from the institutional review board to do so. Only stakeholder working in insurance company had an opposite stance about the cost-effectiveness of genomic medicine and pharmacogenomics.

A.1.4. Stance of the Stakeholders' Strategy of the Implementation of Genomic Medicine and

Pharmacogenomics: Albeit Preemptive Approach or

Gene-Specific Approach:

The majority of the stakeholders favored preemptive approach which seeks testing proactively once in lifetime and having the results of the genetic test ready at time of prescribing.

"If you have proper equipment and proper screening then preemptive absolutely, as you do more help there right? you don't wait for the patient to become patient to react." Stakeholder\#5

They had 2 approaches though; some supported newborn screening preemptive approach, while others preferred premarital screening preemptive approach. Genetic counselors' attitude was skewed toward gene-specific approach because they anticipated the dilemma of incidental findings.

\section{A.1.5. Attitude about Their Desire to Undertake}

Genetic Test:

We had mixed results, many agreed to undertake the genetic test to have better control of their life and to have 
a motive to lead a healthy lifestyle, and on the other hand, many disclosed that they will not take the test as they are scared of the consequences.

"I would not do it for myself, it will open a door I will not be able to close." Stakeholder\# 1

Those who have children were more inclined to conduct the tests on their children but not themselves.

\section{A.1.6. Attitude toward Online Direct to Consumer Kit:}

Most of the stakeholder's attitude about online directto-consumer kit was skewed toward rejecting them. Their justification for this stand is represented in the words of one of the genetic counselors:

"I think it is misleading the consumer, it is not giving them correct and clear information, and the client walking away thinking that he had been tested for everything under the sun and he is immune now and that is not true. I really believe that counseling should support the testing everywhere and every time." Stakeholder\#4

\section{A.2.1 Concerns about the Ethical and Legal Aspects} of Genomic Medicine:

Stakeholders exhibit blended views with regard to the ethical and legal aspects of genomic medicine. Some of them did not voice any concern about any ethical or legal consequences of genomic medicine. Others were occupied with concerns related to confidentiality of the genetic tests results especially with the use of cloud for bioinformatics. Many worried about the ramification of disclosing genetic tests results to insurance companies. As they are anxious that insurance companies may increase the insurance price (this concern was confirmed by stakeholder from insurance company) or discrimination by employer by denying jobs to those with high probability of having a disease. Few of the stakeholders had not thought about it nor consider it in their planning agenda.

\section{A.2.2. Stakeholders Perceived Barriers and}

Challenges for the Full Implementation of Genomic Medicine and Pharmacogenomics in UAE:

The barriers and challenges perceived by the stakeholders in UAE can be categorized using the PESTLE tool borrowed from the business model of risk management [40] as follows:

- $\mathbf{P}=$ Political: the slow pace of implementation, fragmented system and lack of unity, and ineffective regulation of curriculum by professional bodies and health regulators.

- $\mathbf{E}=$ Economic: cost of bioinformatics support and coverage of the genetic tests to all citizens.
- $\mathbf{S}=$ Social: confidentiality, apathetic and latent stakeholders, ignorance, lack of awareness about genomic medicine in UAE community, role of media.

- $\mathbf{T}=$ Technological: Bioinformatics.

- $\quad \mathrm{L}=$ Legal: Ineffective regulation of curriculum by professional bodies and health regulators.

- $\mathbf{E}=$ Environmental: Lack or the gap in education about genomic medicine and pharmacogenomics, lack of evidence-based pertaining to UAE population, ineffective regulation of curriculum by professional bodies and health regulators, ineffective curriculum, lack of experts in the field whether in the academic field or the health setting and limited numbers of well-trained genetic counselors.

\section{Emerging Themes}

The inductive methodology allowed us to code emerging themes that we did not envision in our objectives. The emerging themes are the added value of genetic counselor and the role of media as a stakeholder in the awareness of genetic diseases. Below is an elaboration on these themes.

B.1. Stance of the Stakeholders of the Added Value of Genetic Counselors:

The added value of genetic counselors emerged when talking to stakeholders in the health setting as well as academic fields. They pointed out that the genetic counselor is the proposed model that will address the gap in the knowledge of genomics among healthcare providers. Thus, their role is crucial for guiding physicians, saving cost and timely intervention as well as their traditional role of counseling the index case and their pedigree.

"Those physicians who are not competent in genomics, the genetic counsellor will actually go to the round with them, so she recommends microarrays or gene panel for epilepsy for example or if it is a more complex case, she guide and navigate the doctors to find the cost-effective route and test. When the results are back, all of them need help with what does the result mean? so our genetic counsellor will do both, she will talk to the family and explain the result and its consequences, also the genetic counsellor will talk to the doctors to explain what these results mean in term of management of the disease. For example, is the results diagnostic findings or not, maybe they need axiom sequence instead of microarray. She will explain the etiology as well. Some doctors can do that, but the current model even in the State they have genetic consoler in every specialty to do that, and in UAE with the burden of disease and lack of healthcare providers you need to depend on genetic counselor" Stakeholder\#5. 


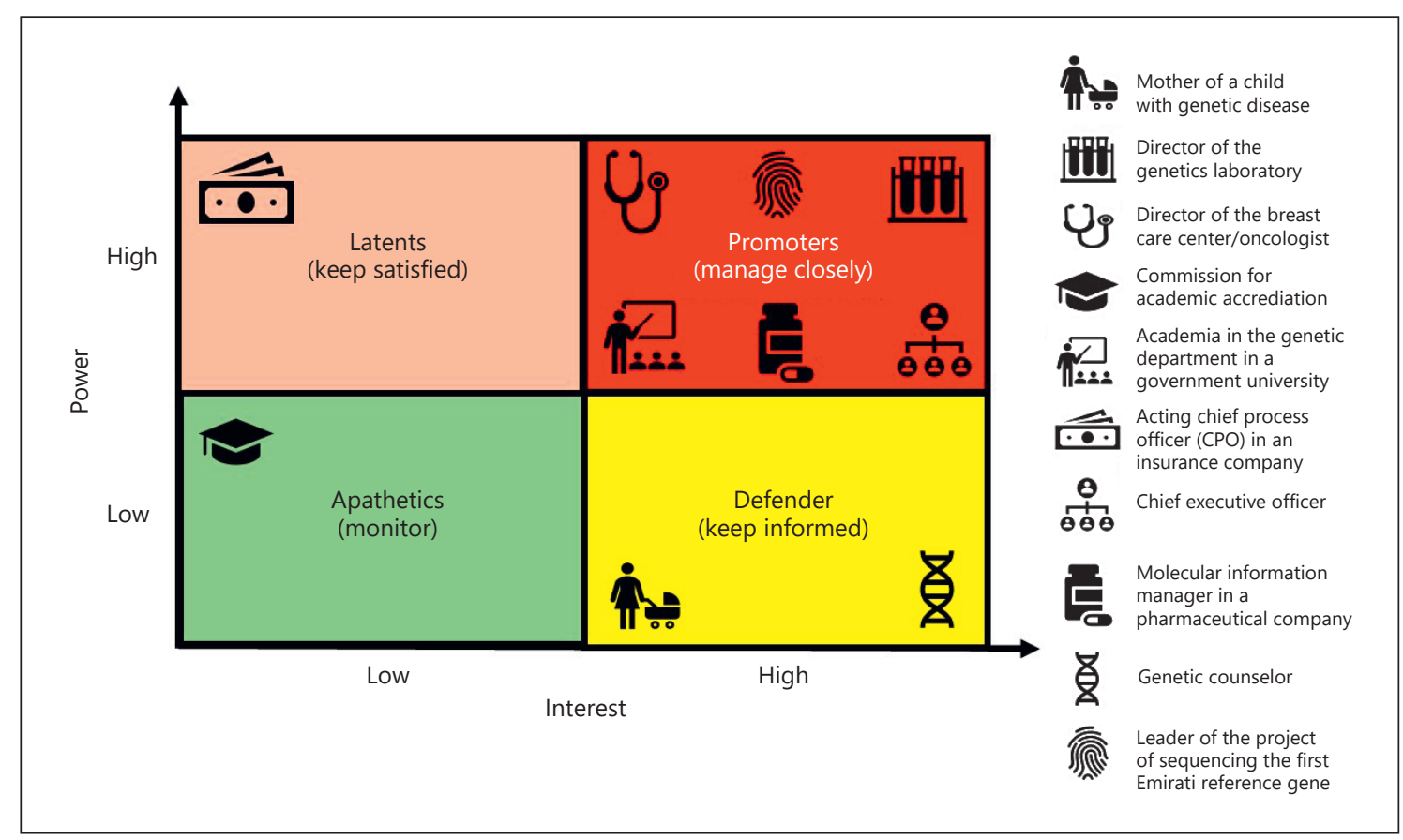

Fig. 2. Mendelow's matrix of the interviewed stakeholders. CPO, chief process officer.

B.2. Role of Media in the Awareness about Genomic Medicine and Genetic Diseases:

The mother of the child with genetic disorder voiced out that media role is lagging behind in spreading awareness about genetic diseases and the value of genomic medicine.

"My daughter is a teenager now, and her peers are giving her a hard time at school, most of the time she comes home crying and there is nothing I can do, I cannot educate them or ask their families to do so. Unfortunately, the media did not bring justice to children with genetic diseases, as they are always viewed as retarded. My daughter is not retarded, and she should not go through all this pain and sadness. That added extra weight on my shoulders" Stakeholder\#13.

\section{Mendelow's Matrix}

We mapped the interest and power (Mendelow's matrix) of the stakeholders in UAE, based on the preponderance of the emanated themes using a deductive methodological approach. Figure 2 visualizes this mapping.

The Mendelow's model of the stakeholders in UAE (Fig. 2) is an essential and validated strategic step in the business management that will empower policy makers and interested parties to empower a full implementation of genomic medicine and pharmacogenomics. The fol- lowing categorization of the types of stakeholders identified through using Mendelow's model will provide a systematic communication and action plan strategy for future genomic medicine and pharmacogenomics implementation [24]. The first category identified is the promoters for full implementation of genomic medicine and pharmacogenomics in UAE are in this study, they are researchers and academics healthcare administrative, and pharmaceutical companies. As per the stakeholders' model, the strategy to deal with important and interested stakeholders is to manage closely as they are the key players. The second category which lies on the other side of the spectrum is stakeholders with low interest and low power (the apathetic); in our study they are the commission for academic accreditation. According to Mendelow's model, so the recommended strategy is to keep them under monitoring without engaging them in the plan of the implementation. Third category includes the stakeholders with high power but low interest. These are the real challenge (the latent). In our study, they are the insurance company, so the panacea is to keep them satisfied and engaged. Finally, the last category are stakeholders is those with high interest but low power (the defenders), in our sample they are the genetic counselors and parents of the child with genetic disorder; they ought to be informed and engaged. 


\section{Discussion/Conclusion}

Stakeholders in healthcare systems are the major team players and mapping their role, power, interest, and stance is a critical consideration for implementing genomic medicine and pharmacogenomics [21]. This will support shaping the roadmap of genomic medicine and pharmacogenomics in the UAE. Boasting standard policies will set up the stage for robust systems in the country.

Role of stakeholders in operationalizing genomic medicine and pharmacogenomics in healthcare and educational systems had been studied extensively. Mitropoulou et al. [21] stated that mapping the views of stakeholder's paves the road for standardizing national policies. In a recent qualitative study, Best et al. [16] concluded that pinpointing areas of discrepancies or cohesions among stakeholders will guide in meeting their needs. The literature review carried out by Roberts et al. [41] identified the role of stakeholders as a prospect for implementing genomic medicine.

The qualitative nature of our study allowed us to dig deep into the stance and interest of stakeholders in UAE. Most of the stakeholders in this study ascertained the clinical demand of genomic medicine in UAE. They aligned this demand with the high prevalence of consanguinity in UAE, the high burden of genetic diseases, the urge to utilize the genomic technology to personalized medications, and the increased awareness among physicians about the power of genetic services that motivated them to demand genomic medicine. These rationalizations are backed by research conducted in UAE, for instance, Denic et al. [42] associated consanguinity with the prevalence of $\beta$-Thalassemia in Abu Dhabi (Abu Dhabi is the capital of UAE). Another study by Al-Jasmi et al. [43] concerning the burden of Lysosomal storage recessive disorder concluded that UAE had 40-folds higher prevalence compared to western countries and that is linked to consanguinity in UAE. Al-Gazali et al. [44] reviewed the mutation of single-gene disorders and they reported that UAE ranked sixth in accordance with the prevalence of birth defects and they attributed that to the norm of consanguinity.

The positive stance of stakeholders in UAE toward the clinical demand of genomic medicine in UAE is comparable to other stakeholders in the world. In their analysis of stakeholders in Greece, Mitropoulou et al. [25] reported similar findings, though in their study they did not have unity as both the Ministry of Health and public healthcare insurance funds were on opposite stance.
Infrastructure is one of the robust pillars for the implementation of genomic medicine and pharmacogenomics [21]. Many of the stakeholders in UAE favored building an internal infrastructure in the country over the current norm of sending and processing genetic samples abroad. They expressed the fact that UAE is a wealthy country and can afford building this infrastructure. Interestingly, one of the interviewed stakeholders was responsible for building an internal capacity in UAE, and their first project is the Genome Program to sequence Emirati reference genome. The stakeholder agreed that having an internal infrastructure will troubleshoot any issues related to privacy, extra cost, and the delay in receiving the results. Whereas those stakeholders working as chief executive officers and other administrative roles preferred to wait till a demand is able to bring return on investment. That is in line with the stakeholders in Greece who voiced resources as one of the obstacles and challenges for full implementation of genomic medicine and pharmacogenomics [25].

There had been other projects to sequence the human genome in UAE as well as its neighboring countries: Kuwait, Saudi Arabia, and Qatar [45]. However, the stakeholders warned that the scattered and fragmented nature of these projects did not add value to the target of having UAE database or even GCC database. Evidence from other studies underscored such issue of fragmentation and recommended having a governance committee with proactive measures [46].

Most of the stakeholders in our sample viewed genomic medicine and pharmacogenomics as cost-effective. One of the stakeholders disclosed that they are in the process of studying this in UAE and got the green light from the institutional review board to do so. This demeanor leverages the implementation of genomic medicine and pharmacogenomics in UAE as numerous researches provided evidence pertaining to the cost-effectiveness of genomic medicine and pharmacogenomics [47-51].

However, stakeholder working in insurance company had an opposite stance about the cost-effectiveness of genomic medicine and pharmacogenomics in UAE. This attitude raises a red flag. Reimbursement has been identified by Implementing GeNomics In pracTicE (IGNITE) network as one of the 7 key drivers of genomic sustainability [52]. Levy et al. [52] stated that embracing genomic medicine is challenged by evidence considered necessary for payers to vindicate reimbursement. A study by Hess et al. [53] was in line with our findings, and they justified the attitude of insurance companies that they are viewing pharmacogenomic tests as experimental not clin- 
ical. Further research is needed to analyze this attitude and uncover its explanation to overcome this obstacle in its infancy stage in UAE.

The debate about the best approach for implementing genomic medicine and pharmacogenomics is a hot topic in research; [54-57] we articulate this in our interview guide. The majority of the stakeholders in UAE favored preemptive approach which seeks testing proactively once in lifetime and having the results of the genetic test ready at time of prescribing over the gene-specific approach. Only the 2 genetic counselors in our cohort were skewed toward gene-specific approach because they anticipated the dilemma of incidental findings [58].

On the same theme of genetic testing, most of the stakeholders in UAE are opposing online direct-to-consumer kits. They attributed that to lack of awareness among the community in UAE, lack of regulation, and the missing piece of counseling by genetic counselor that are not offered by most direct-to-consumer kits. These attributes had been addressed in research. Schleit et al. [59] discussed a case of a false-negative result, and how it poses harm not only for the person taking the test but also to their relatives. Direct to consumer is not yet licensed in UAE; however, stakeholders are occupied with health and safety of the UAE community and voiced the need to have regulations in place to protect and educate consumers. Moreover, they proposed the alternative of accredited clinic-based tests with affordable prices, which are coupled with genetic counseling service [21, 25, 59-62].

On the verge of the implementation of genomic medicine and pharmacogenomics in UAE, some of the stakeholders are occupied with ethical and legal concerns whereas, few stakeholders have not thought about it. These concerns had been consolidated in literature, to name few: confidentiality of the results of genetic test in the cloud era, insurance discrimination, and employer discrimination [63-65]. These findings are in line with the concerns of stakeholders in Greece [25] and USA [64]. One of the stakeholders foresees the need to modify consent process and adopt dynamic consent process instead. This is a trajectory that requires enforcing laws and legislation to protect privacy, confidentiality, and autonomy of the patients [66-68]. Overall, we consider this a pressing need to address before it becomes a barrier [21].

An imperative exploration from our interview of stakeholders is the list of anticipated barriers and challenges for the full implementation of genomic medicine and pharmacogenomics in UAE. Identifying these risk variables gives the stakeholders, a vantage point to proactively overcome these barriers. Addressing these risks by the experts will pave the way to the full implementation of genomic medicine and pharmacogenomics in UAE $[40,69]$. Implementing the strategies dictated by the Mendelow's business model will allow the systematic implementation of genomic medicine and pharmacogenomics besides it will facilitate saving time and resources by engaging the key players (promoters and defenders) as well as engaging and satisfying the latent stakeholder [24, 70-73].

To our knowledge, this study is the first attempt to explore the attitude and stance of the stakeholders in the UAE. The qualitative methodology allowed us to map the power/interest matrix of Mendelow's model which is a substantial footstep for achieving the full implementation of genomic medicine and pharmacogenomics in UAE.

Similar to other qualitative studies, the shortcoming of generalization is the inheritance limitation in this study. However, we set the stage for conducting quantitative studies to satisfy generalization. Another limitation is lack of representation of the media, pharmacists, religious authority, and other stakeholders. Nevertheless, we were able to map various stakeholders representing different sectors of the UAE. We insured the credibility, reliability, and quality of our research by insuring the Lincoln and Guba's [74] evaluation criteria: triangulation, respondent validation reflexivity, peer debriefing, and audit trail, as well as, using validated tools and models from the business arena.

\section{Conclusions}

We foresee our findings as the launching point for establishing a strategy for the implementation of genomic medicine and pharmacogenomics in UAE. This will facilitate the construction of a roadmap for the full implementation of genomic medicine and pharmacogenomics in the UAE with potential applicability to many healthcare systems around the world. The mapping of stakeholders in UAE is a key element in the road map. We recommend building on these finding by conducting a quantitative research and to be replicated on different timelines to capture the dynamic stance and interest of stakeholders in UAE.

\section{Acknowledgement}

The authors would like to thank and acknowledge the stakeholders who accepted to take part in this qualitative study. 


\section{Statement of Ethics}

This study had been approved by social science research Ethics Committee of United Arab Emirates University (UAEU) ERS_2017_5671. Participants were asked to read the information sheet of the study as well as to sign the consent form before starting the interview.

\section{Conflict of Interest Statement}

The authors have no conflicts of interest to declare.

\section{Funding Sources}

This study is supported by a grant from UAEU, Zayed Center for Health Sciences, UAE University Fund code 31R175. The pharmacogenomics work of BRA is supported by UAEU and the UAE Ministry of Education. The sponsor has no roles in the preparation and analysis of data or the manuscript. No incentives were given to the stakeholders to participate.

\section{Author Contributions}

F.M., A.R., I.A., L.A., B.R.A., and G.P. conceived and planned the study. A.R. and I.A. developed the interview guide, verbatim the transcripts, analyzed the data, and drafted the manuscript. F.M., L.A., B.R.A., and G.P. reviewed the interview guide and the interpretation. All the authors read, edited, and approved the final version of the manuscript.

\section{References}

1 Shendure J, Findlay GM, Snyder MW. Genomic medicine-progress, pitfalls, and promise. Cell. 2019;177(1):45-57.

2 Green RF, Ari M, Kolor K, Dotson WD, Bowen S, Habarta N, et al. Evaluating the role of public health in implementation of genomicsrelated recommendations: a case study of hereditary cancers using the CDC Science Impact Framework. Genet Med. 2019;21(1):28.

3 Evans WE, Pui CH, Yang JJ. The promise and the reality of genomics to guide precision medicine in pediatric oncology: the decade ahead. Clin Pharmacol Ther. 2020;107(1): 176-80.

4 Geiersbach KB, Chen H, Emmadi R, Haskell GT, Lu X, Liu YJ, et al. Current concepts in breast cancer genomics: an evidence based review by the CGC breast cancer working group. Cancer Genet. 2020;244:11-20.

5 Lucas JS, Davis SD, Omran H, Shoemark A. Primary ciliary dyskinesia in the genomics age. Lancet Respir Med. 2020;8(2):202-16.

6 Monaghan KG, Leach NT, Pekarek D, Prasad $\mathrm{P}$, Rose NC. The use of fetal exome sequencing in prenatal diagnosis: a points to consider document of the American College of Medical Genetics and Genomics (ACMG). Genet Med. 2020;22(4):675-80.

7 Neill SG, Hauenstein J, Li MM, Liu YJ, Luo M, Saxe DF, et al. Copy number assessment in the genomic analysis of CNS neoplasia: an evidence-based review from the cancer genomics consortium (CGC) working group on primary CNS tumors. Cancer Genet. 2020 May; 243:19-47.

8 Riggs ER, Andersen EF, Cherry AM, Kantarci S, Kearney H, Patel A, et al. Technical standards for the interpretation and reporting of constitutional copy-number variants: a joint consensus recommendation of the American College of Medical Genetics and Genomics (ACMG) and the Clinical Genome Resource (ClinGen). Genet Med. 2020;22(2):245-57.
9 Uddin M, Mustafa F, Rizvi TA, Loney T, Al Suwaidi H, Al-Marzouqi AHH, et al. SARSCoV-2/COVID-19: viral genomics, epidemiology, vaccines, and therapeutic interventions. Viruses. 2020;12(5):526.

10 Murray MF, Kenny EE, Ritchie MD, Rader DJ, Bale AE, Giovanni MA, et al. COVID-19 outcomes and the human genome. Genet Med. 2020 Jul;22(7):1175-77.

11 Randhawa GS, Soltysiak MPM, El Roz H, de Souza CPE, Hill KA, Kari L. Machine learning using intrinsic genomic signatures for rapid classification of novel pathogens: COVID-19 case study. PLoS One. 2020;15(4):e0232391.

12 Brunette CA, Miller SJ, Majahalme N, Hau C, MacMullen L, Advani S, et al. Pragmatic trials in genomic medicine: the integrating pharmacogenetics in clinical care (I-PICC) study. Clin Transl Sci. 2020;13(2):381-90.

13 Kochan DC, Winkler E, Lindor N, Shaibi GQ, Olson J, Caraballo PJ, et al. Challenges in returning results in a genomic medicine implementation study: the Return of Actionable Variants Empirical (RAVE) study. NPJ Genom Med. 2020;5(1):19-7.

14 Lauschke VM, Ingelman-Sundberg $M$. Emerging strategies to bridge the gap between pharmacogenomic research and its clinical implementation. NPJ Genom Med. 2020; 5(1):1-7.

15 McClaren BJ, King EA, Crellin E, Gaff C, Metcalfe SA, Nisselle A. Development of an evidence-based, theory-informed national survey of physician preparedness for genomic medicine and preferences for genomics continuing education. Front Genet. 2020;11:59.

16 Best S, Stark Z, Phillips P, Wu Y, Long JC, Taylor N, et al. Clinical genomic testing: what matters to key stakeholders? Eur J Hum Genet. $2020 \mathrm{Jul}: 28(7): 866-73$.
17 Klein RD. Current policy challenges in genomic medicine. Clin Chem. 2020;66(1):617.

18 McClaren BJ, Crellin E, Janinski M, Nisselle AE, Ng L, Metcalfe SA, et al. Preparing medical specialists for genomic medicine: continuing education should include opportunities for experiential learning. Front Genet. 2020; 11:151.

19 Zgheib NK, Patrinos GP, Akika R, Mahfouz R. Precision medicine in low- and middle-income countries. Clin Pharmacol Ther. 2020; 107(1):29-32.

20 Chenoweth MJ, Giacomini KM, Pirmohamed M, Hill SL, Schaik RHN, Schwab M, et al. Global pharmacogenomics within precision medicine: challenges and opportunities. Clin Pharmacol Ther. 2020;107(1):57-61.

21 Mitropoulou C, Politopoulou K, Vozikis A, Patrinos GP. Assessing the stakeholder landscape and stance point on genomic and personalized medicine. Applied genomics and public health. Elsevier; 2020. p. 211-23.

22 Mustapa MAC, Amin L, Mahadi Z. Determinants of stakeholders' intention to adopt pharmacogenomic. Pharmacogenomics J. 2020 Dec;20(6):801-12.

23 Rigter T, Jansen ME, de Groot JM, Janssen SWJ, Rodenburg W, Cornel MC. Implementation of pharmacogenetics in primary care: a Multi-stakeholder perspective. Front Genet. 2020;11:10.

24 Mendelow AL. Environmental scanning-the impact of the stakeholder concept. p. 20.

25 Mitropoulou C, Mai Y, Van Schaik RH, Vozikis A, Patrinos GP. Stakeholder analysis in pharmacogenomics and genomic medicine in Greece. Public Health Genomics. 2014;17(56):280-6.

26 Altahtooh U. Why take PMP rather than prince 2 in project management in Saudi Arabia? Eur J Business Manag Res. 2020;5(3) 
27 Bernstein SL, Weiss J, Curry L. Visualizing implementation: contextual and organizational support mapping of stakeholders (COSMOS). Implement Sci Commun. 2020; $1: 48-11$.

28 Potnis DD, Gala B. Managing the "backend" of LIS research projects: a project management perspective. Lib Inf Sci Res. 2020;42(1): 100996.

29 Chanfreau-Coffinier C, Peredo J, Russell MM, Yano EM, Hamilton AB, Lerner B, et al. A logic model for precision medicine implementation informed by stakeholder views and implementation science. Genet Med. 2019; 21(5):1139-54.

30 Esquivel-Sada D, Lévesque E, Hagan J, Knoppers BM, Simard J. Envisioning implementation of a personalized approach in breast cancer screening programs: stakeholder perspectives. Healthc Policy. 2019;15(2):39-54.

31 Faulkner E, Holtorf A-P, Walton S, Liu CY, Lin H, Biltaj E, et al. Being precise about precision medicine: what should value frameworks incorporate to address precision medicine? A report of the Personalized Precision Medicine Special Interest Group. Value Health. 2020 Apr;23(5).

32 Jithesh PV, Scaria V. From genomes to genomic medicine: enabling personalized and precision medicine in the Middle East. Per Med. 2017 Sep;14(5):377-82.

33 Al-Mahayri ZN, Al Jaibeji HS, Saab Y, Soliman K, Al-Gazali L, Patrinos GP, et al. VKORC1 variants as significant predictors of warfarin dose in Emiratis. Pharmgenomics Pers Med. 2019;12:47.

34 Alblooshi H, Al Safar H, Fisher HF, Cordell HJ, El Kashef A, Al Ghaferi H, et al. A casecontrol genome wide association study of substance use disorder (SUD) identifies novel variants on chromosome 7p14. 1 in patients from the United Arab Emirates (UAE). Am J Med Genet B Neuropsychiatr Genet. 2019 Jan;180(1):68-79.

35 AlSafar HS, Al-Ali M, Elbait GD, Al-Maini $\mathrm{MH}$, Ruta D, Peramo B, et al. Introducing the first whole genomes of nationals from the United Arab Emirates. Sci Rep. 2019;9(1): 14725-15.

36 Osman WM, Jelinek HF, Tay GK, Hassan $\mathrm{MH}$, Almahmeed W, Khandoker AH, et al. Genetics of diabetic kidney disease: a followup study in the Arab population of the United Arab Emirates. Mol Genet Genomic Med. 2019;7(12):e985.

37 Strauss A, Corbin J. Basics of qualitative research techniques. Thousand Oaks, CA: Sage publications; 1998.

38 Groenland E. Employing the matrix method as a tool for the analysis of qualitative research data in the business domain. Int J Glob Small Bus. 2018;21(1):119-34.

39 O’Brien BC, Harris IB, Beckman TJ, Reed DA, Cook DA. Standards for reporting qualitative research: a synthesis of recommendations. Acad Med. 2014;89(9):1245-51.
40 Rastogi N, Trivedi MK. PESTLE technique-a tool to identify external risks in construction projects. Int Res J Eng Technol. 2016;3(1): 384-8.

41 Roberts JS, Gornick MC, Carere DA, Uhlmann WR, Ruffin MT, Green RC. Direct-toconsumer genetic testing: user motivations, decision making, and perceived utility of results. Public Health Genomics. 2017;20(1): 36-45.

42 Denic S, Aden B, Nagelkerke N, Essa AA. $\beta$-Thalassemia in Abu Dhabi: consanguinity and tribal stratification are major factors explaining the high prevalence of the disease. Hemoglobin. 2013;37(4):351-8.

43 Al-Jasmi FA, Tawfig N, Berniah A, Ali BR, Taleb M, Hertecant JL, et al. Prevalence and novel mutations of lysosomal storage disorders in United Arab Emirates. JIMD ReportsVolume 10. Springer; 2012. p. 1-9.

44 Al-Gazali L, Ali B. Mutations of a country: a mutation review of single gene disorders in the United Arab Emirates (UAE). Hum Mutat. 2010 May;31(5):505-20.

45 Al-Ali M, Osman W, Tay GK, AlSafar HS. A 1000 Arab genome project to study the Emirati population. J Hum Genet. 2018;63(4): 533-6.

46 Cornel MC, van El CG, Dondorp WJ. The promises of genomic screening: building a governance infrastructure. Special issue: genetics and democracy. J Community Genet. 2012;3(2):73-7.

47 Fragoulakis V, Bartsakoulia M, Díaz-Villamarín X, Chalikiopoulou K, Kehagia K, Ramos JGS, et al. Cost-effectiveness analysis of pharmacogenomics-guided clopidogrel treatment in spanish patients undergoing percutaneous coronary intervention. Pharmacogenomics J. 2019;19(5):438-45.

48 Girardin FR, Poncet A, Perrier A, Vernaz N, Pletscher M, Samer C, et al. Cost-effectiveness of HLA-DQB1/HLA-B pharmacogeneticguided treatment and blood monitoring in US patients taking clozapine. Pharmacogenomics J. 2019;19(2):211-8.

49 Kasztura M, Richard A, Bempong N-E, Loncar D, Flahault A. Cost-effectiveness of precision medicine: a scoping review. Int J Public health. 2019 Dec;64(9):1261-71.

50 Stark Z, Schofield D, Martyn M, Rynehart L, Shrestha R, Alam K, et al. Correction: does genomic sequencing early in the diagnostic trajectory make a difference? A follow-up study of clinical outcomes and cost-effectiveness. Genet Med. 2019;21(2):516-6.

51 Zhang L, Bao Y, Riaz M, Tiller J, Liew D, Zhuang X, et al. Population genomic screening of all young adults in a health-care system: a cost-effectiveness analysis. Genet Med. 2019:1.

52 Levy KD, Blake K, Fletcher-Hoppe C, Franciosi J, Goto D, Hicks JK, et al. Correction: opportunities to implement a sustainable genomic medicine program: lessons learned from the IGNITE Network. Genet Med. 2019; 21(7):1670-0.
53 Hess GP, Fonseca E, Scott R, Fagerness J. Pharmacogenomic and pharmacogeneticguided therapy as a tool in precision medicine: current state and factors impacting acceptance by stakeholders. Genet Res. 2015;97: e13.

54 Hart MR, Garrison LP Jr, Doyle DL, Jarvik GP, Watkins J, Devine B. Projected cost-effectiveness for 2 gene-drug pairs using a multigene panel for patients undergoing percutaneous coronary intervention. Value Health. 2019;22(11):1231-9.

55 Leary E, Brilliant M, Peissig P, Griesbach S. Preliminary outcomes of preemptive warfarin pharmacogenetic testing at a large rural healthcare center. Am J Health Syst Pharm. 2019;76(6):387-97.

56 Nallaseth FS. Shifting the therapeutic paradigm in medicine from post mutational $(\&$ pathological) intervention to preemption-a synopsis of the 'nuts and bolts'. MOJ Proteomics Bioinform. 2019;8(2):41-3.

57 Marrero RJ, Cicali EJ, Arwood MJ, Eddy E DeRemer D, Ramnaraign $\mathrm{BH}$, et al. How to transition from single gene pharmacogenetic testing to preemptive panel-based testing: a tutorial. Clin Pharmacol Ther. 2020 Sep; 108: 557-65.

58 Lannoy N, Lambert C, Van Damme A, Hermans C. Incidental finding of unreported large duplication in F8 gene during prenatal analysis: which management for genetic counselling? Thromb Res. 2019;182:39-42.

59 Schleit J, Naylor LV, Hisama FM. First, do no harm: direct-to-consumer genetic testing. Genet Med. 2019;21(2):510-1.

60 Tandy-Connor S, Guiltinan J, Krempely K, LaDuca H, Reineke P, Gutierrez S, et al. Falsepositive results released by direct-to-consumer genetic tests highlight the importance of clinical confirmation testing for appropriate patient care. Genet Med. 2018;20(12):1515.

61 Schaper M, Wöhlke S, Schicktanz S. "I would rather have it done by a doctor": laypeople's perceptions of direct-to-consumer genetic testing (DTC GT) and its ethical implications. Med Health Care Philos. 2019;22(1):31-40.

62 Weedon MN, Jackson L, Harrison JW, Ruth KS, Tyrrell J, Hattersley AT, et al. Very rare pathogenic genetic variants detected by SNPchips are usually false positives: implications for direct-to-consumer genetic testing. bioRxiv. 2019:696799.

63 Dove ES, Joly Y, Tassé AM, Knoppers BM, au, Knoppers BM. Genomic cloud computing: legal and ethical points to consider. Eur J Hum Genet. 2015;23(10):1271-8.

64 Bélisle-Pipon J-C, Vayena E, Green RC, Cohen IG. Genetic testing, insurance discrimination and medical research: what the United States can learn from peer countries. Nature Med. 2019;25(8):1198-204.

65 Jooma S, Hahn MJ, Hindorff LA, Bonham VL. Defining and achieving health equity in genomic medicine. Ethn Dis. 2019;29(Suppl 1): 173. 
66 Manson NC. The biobank consent debate: why 'meta-consent' is not the solution? J Med Ethics. 2019;45(5):291-4.

67 Tindana P, Molyneux S, Bull S, Parker M. 'It is an entrustment': broad consent for genomic research and biobanks in sub-Saharan Africa. Dev World Bioeth. 2019;19(1):9-17.

68 Meagher KM, Curtis SH, Gamm KO, Sutton EJ, McCormick JB, Sharp RR. At a moment's notice: community advisory board perspectives on biobank communication to supplement broad consent. Public Health Genomics. 2020;23(1-2):1-13.
69 Walters G, Kitchin P. Stakeholder management and sport facilities: a case study of the Emirates Stadium. 2009.

70 Gottschalk P. Strategic information systems planning: the IT strategy implementation matrix. Eur J Inf Syst. 1999;8(2):107-18.

71 Anney VN. Ensuring the quality of the findings of qualitative research: looking at trustworthiness criteria. J Emerging Trends Educ Res Policy Stud. 2014;5(2):272-81.
72 Kuzmin O, Khilukha O. Regulation of stakeholders' interests in corporate governance through negotiations. Econ Ann-XXI. 2016(161):56-60

73 Elsaid A, Salem R, Kader HA. A dynamic stakeholder classification and prioritization based on hybrid rough-fuzzy method. J Softw Eng. 2017;11(2):143-59.

74 Lincoln YS, Guba EG. But is it rigorous? Trustworthiness and authenticity in naturalistic evaluation. New Dir Program Eval. 1986; 1986(30):73-84. 